Editorial Article

Open Access

\title{
Why a Recently -Discovered Host-Defense Factor, HDFx, May Ameliorate and Prevent Inflammatory Lesions Induced by Sarcoidosis
}

\author{
Burton M Altura ${ }^{1-6}$ and Bella T Altura ${ }^{1,3-6}$

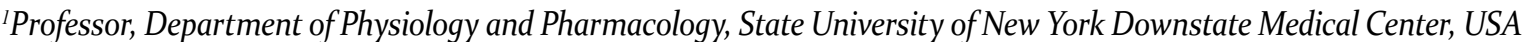 \\ ${ }^{2}$ Professor, Department of Medicine, State University of New York Downstate Medical Center, USA \\ ${ }^{3}$ Professor, The Center for Cardiovascular and Muscle Research, USA \\ ${ }^{4}$ Professor, The School of Graduate Studies in Molecular and Cellular Science, State University of New York, Downstate Medical Center, \\ Brooklyn, New York, USA \\ ${ }^{5}$ Professor, Bio-Defense Systems, Rockville Centre, New York, USA \\ ${ }^{6}$ Professor, Orient Biomedica, Estero, Florida, USA
}

\section{Article Info}

\author{
*Corresponding author: \\ Burton M Altura \\ Professor \\ Department of Physiology and \\ Pharmacology \\ SUNY Downstate Medical Center \\ Brooklyn, NY 11203 \\ USA \\ Tel: 718-270-2194 \\ E-mail: burton.altura@downstate.edu
}

Received: January 30, 2018

Accepted: February 21, 2018

Published: February 21, 2018

Citation: Altura BM, Altura BT. Why a Recently-Discovered Host-Defense Factor, HDFx, May Ameliorate and Prevent Inflammatory Lesions Induced by Sarcoidosis. Madridge J Immunol. 2018; 2(1): 40-42. doi: $10.18689 / \mathrm{mjim}-1000109$

Copyright: (c) 2018 The Author(s). This work is licensed under a Creative Commons Attribution 4.0 International License, which permits unrestricted use, distribution, and reproduction in any medium, provided the original work is properly cited.

Published by Madridge Publishers
Sarcoidosis is a very rare disease of the immune system whereby numerous inflammatory cells, known as granulomas, attack many body organs, particularly the lungs and lymph nodes [1-3]. It seems to have a predilection to attack people between the ages of 20 and 40, and often recedes without any treatment. But, in severe cases, sarcoidosis becomes chronic and will cause permanent cellular damage to numerous organs within the body and, often, death when the inflamed nodules interfere with cardiac function [1]. Unfortunately, the cause(s) of the disease process is not known, nor is there any known cure [1-3]. Sometimes, if caught early enough, administration of corticosteroids will relieve many of the symptoms $[1,2,4]$. Most often, the disease process proceeds without the patient knowing it. The ensuing chronic inflammations lead to permanent thickening or scarring of multiple organ-tissues [1-3]. In the USA, alone, about 200,000 people currently have the active disease [1]. The sarcoidosis mortality rate is approximately $5 \%[1,5]$.

Keywords: Cytokine storms; Lymphocytes; Macrophages; Monocytes; Guinea-pigs.

Interestingly, the granulomas, found in the lungs in sarcoidosis, are composed of macrophages, epitheliod cells, and multinucleated giant cells surrounded by T-lymphocytes, monocytes, mast cells, and fibroblasts [for review, see 1]. These granulomas are thought to arise from an exaggerated cell-mediated immune response to one or more unidentified antigen (s) [1]. Despite some of the best scientists, working to identify the antigen (s), this has remained elusive $[1,6,7]$. There is, however, considerable agreement that alterations/activation in the pathophysiology of alveolar macrophages and T-lymphocytes, leading to alveolitis, are critical in the progression of the disease [1-3], [6,7].

In view of the obvious roles of macrophages in production of sarcoidosis -induced alveolitis, we believe that a reasonable therapeutic avenue would be to prevent/ ameliorate activation of the alveolar macrophages.

Another major problem in preventing lung damage in sarcoidosis is the massive release of cytokines, often leading to undetected "cytokine storms" [for review, see 1]. In this phase of the disease, multiple cytokines are released from lymphocytes, macrophages, and monocytes which perforce act to release other dangerous molecules such as IL-2, TNF-alpha, GM-CSF, MCP-1, interferon-gamma, and a variety 
of chemoattractants, chemokines and growth factors $[1,6]$. Collectively, these substances, in conjunction with the continual release of multiple cytokines, can result in further clumping of cells in the lung capillaries and blockage of pulmonary blood flows and ischemia of the lung parenchyma causing irreversible death of multiple lung tissue segments $[1,6,7]$. So, any "true" therapeutic treatment, in our opinion, should be able to not only prevent/block release of the dangerous cytokines and chemokines, but should be able to open-up blocked capillaries leading to tissue perfusion. In addition, an important aspect of any therapeutic modality should, hopefully, lead to tissue repair and regeneration. Can any known therapeutic molecule (s), potentially, prevent/ameliorate the granulomas and alveolitis, the release of cytokines and chemokines, increase tissue perfusion, and help with lung tissue regeneration? Since sarcoidosis is an inflammatory disease and is seen worldwide, it may have more than one etiology. As has been suggested more than 30 years ago, its manifestations may have an underlying, infectious bacterial component(s) [for recent review, see 8]. The presence of cytokines such as IL-2, IL-4, IL-6, IL-10, TNF-alpha, IL-12, IL-15, and IL-18 as well as chemokines in sarcoidosis may, indeed, be suggestive of the presence of infectious bacterial microorganisms. So, it is logical to us to conclude that agents which could prevent the activation of macrophages, monocytes, and T-lymphocytes which produce, and release, these cytokines and chemokines, in patients with sarcoidosis, should be helpful as prophylactic and therapeutic agents.

\section{Discovery of HDFx and The Rationale for Its Use in Sarcoidosis}

For more than five decades, our laboratories have been working on a new approach to develop host-defense factors that stimulate/and inhibit various arms of the innate and adaptive immune systems [9-25]. To this end, we have discovered a new host-defense factor, termed "HDFx", that is a conserved protein found in mice, rats, guinea-pigs, rabbits, dogs, pigs, and sub-human primates [26-32], unpublished findings]. More than 135 years ago, Elie Metchnikoff, the great father of immunology, hypothesized that the body, under stressful conditions, might produce powerful immunestimulants which perforce would act on different arms of the innate immune system and serve to protect the host against insults and diseases [33]. Metchnikoff's early studies pointed to the important contributions of macrophages and phagocytic leukocytes to natural (innate) resistance against pathogenic microorganisms. Over the past 40 years, considerable evidence has accumulated to support a strong relationship between the functional (physiological) state of the microcirculation, macrophages-phagocytes, natural killer cells, and the reticuloendothelial system (RES) to host defense and resistance to all types of pathogenic microorganisms, trauma, circulatory shock, diverse infections, and combined injuries which affect multiple organ systems $[1-3,6,7]$.

A large body of experimental studies, from our laboratories, has shown that HDFx is protective (to different degrees) against a wide variety of systemic bodily insults ranging from hemorrhage, trauma (to different organs), endotoxins, a variety of gram-negative and to gram-positive lethal bacteria and fungi (e.g., E.coli, S. enteriditis, C. welchii, mycobacteria, S. aureus, and aspergillous, among others) [26-32], unpublished findings]. Other unique attributes of HDFx are that it can accelerate wound healing, promote tissue regeneration, restore normal microvascular and endothelial cell tone as well as prevent chemoattraction of macrophages, leukocytes, and platelets to the postcapillary venular walls in all tissues, so far investigated (i.e., lung, kidney, heart, intestine, and skeletal muscle) [9,12-14,23-32,34-36] unpublished findings]. In view of these uncanny attributes, we believe that HDFx could be useful in the prevention and treatment of sarcoidosis.

A major thrust for our group is to secure adequate funding to elucidate the complete, complex molecular structure of HDFx and then via genetic engineering to produce large quantities of HDFx for further testing in human subjects and animals to confirm our hypothesis.

\section{Acknowledgements}

Some of the original studies needed for the discovery of HDFx, and reviewed above, were initiated while the authors were at New York University School of Medicine and The Albert Einstein College of Medicine of Yeshiva University. Some of the original studies and experiments reviewed, above, were supported, in part, by unrestricted grants from several pharmaceutical companies (CIBA-GEIGY Corp, Sandoz Pharmaceuticals, The UpJohn Co., and Bayer Pharmaceuticals), Research Grants from The N.I.H., as well as anonymous donors.

\section{References}

1. Iannuzzi MC, Rybicki BA, Teirstein AS. Sarcoidosis. New Engl J Med. 2007; 357: 2153-166. doi: 10.1056/NEJMra071714

2. Torpy JM, Alison E, Burke MA, Golub RM. Sarcoidosis. JAMA. 2011; 305: 423-24. doi: 10.1001/jama.305.4.423

3. Broadway-Duren JB. A systematic review of the literature on sarcoidosis: Early recognition and diagnosis. Immunome Res. 2015; 11(1). doi: 10.4172/1745-7580.1000084

4. Judson MA. The treatment of pulmonary sarcoidosis. Regulatory Med. 2012; 106: 1351-61. doi: 10.1016/j.rmed.2012.01.013

5. Swigris JL, Olson AL, Huie TJ, Fernandez-Perez ER, Solomon J, et al. Sarcoidosis-related mortality in the United States from 1968 to 2011. Am J Resp Dis Crit Care Med. 2011; 183: 1524-30. doi: 10.1164/rccm.201010$16790 \mathrm{C}$

6. Morgenthau AS, lannuzzi MC. Recent advances in sarcoidosis. Chest. 2011; 139: 174-182. doi: 10.1378/chest.10-0188

7. Baydur A. Recent developments in the physiological measurement of sarcoidosis: clinical implications. CurrOpinPulm Med. 2012; 18: 499-505.

8. Esteves T, Aparicio G, Garcia-Patos V. Is there any association between Sarcoidosis and infectious agents?: a systematic review and metaanalysis. BMC Pulmon Med. 2016; 16: 165. doi: 10.1186/s12890-0160332-z

9. Altura BM. Endothelium, reticuloendothelial cells, and microvascular integrity: Roles in host defense. In: Handbook of Shock and Trauma. Altura BM, Lefer AM, Schumer W, eds. Raven Press, New York. 1983; 1: 51-95. 
10. Altura BM. DVAVP: A vasopressin analog with selective microvascular and RES actions for the treatment of circulatory shock in rats. Eur $J$ Pharmacol. 1976; 37: 155-168.

11. Altura BM. Microcirculatory approach to the treatment of circulatory shock with a new analog of vasopressin, [2-phenylalanine, 8-ornithine]vasopressin. J PharmacolExpTher. 1976; 198: 187-96.

12. Altura BM. Sex and estrogens in protection against circulatory stress reactions. Am J Physiol. 1976; 231: 842-47. doi: 10.1152/ajplegacy.1976.231.3.842

13. Altura BM. Reticuloendothelial system and neuro-endocrine stimulation in shock therapy. Adv Shock Res. 1980; 3: 3-25.

14. Altura BM. Microcirculatory regulation and dysfunction: Relation to RES function andresistance to shock and trauma. In: The Reticuloendothelial System. Reichard S, Filkins JP, eds. Plenum Press, New York. 1985; 7: 353-95.

15. Hershey SG, Altura BM. Effects of pretreatment with aggregate albumin on reticuloendothelial system activity and after experimental shock. Proc SocExpBiol Med. 1966; 122: 1195-99. doi: 10.3181/00379727-122-31358

16. Altura BM, Hershey SG. Use of reticuloendothelial phagocytic function as an index in shock therapy. Bull NY Acad Med. 1967; 43: 259-66.

17. Altura BM, Hershey SG. RES phagocytic function in trauma and adaptation to experimental shock. Am J Physiol. 1968; 215: 1414-19. doi: 10.1152/ajplegacy.1968.215.6.1414

18. Hershey SG, Altura BM. Function of the reticuloendothelial system in experimental shock and combined injury. Anesthesiology. 1969; 30: 138-143.

19. Altura BM, Hershey SG. Effects of glyceryl trioleate on the reticuloendothelial system and survival after experimental shock. J PharmacolExpTher. 1970; 175: 555-564.

20. Altura BM, Hershey SG. Sequential changes in reticuloendothelial system function after acute hemorrhage. Proc Soc Exp Biol Med. 1972; 139: 935-39.

21. Altura BM. Glucocorticoid-induced protection in circulatory shock: role of reticuloendothelial system function. Proc SocExpBiol Med. 1975;150: 202-06.

22. Altura BM, Gebrewold A. Prophylactic administration of antibiotics compromises reticuloendothelial system function and exacerbates shock mortality in rats. Eur J Pharmacol. 1980; 68: 19-21.

23. Altura BM. Recent progress in pathophysiology of shock: Reticuloendothelial and neuro-endocrine stimulation. J Clin Anesth. 1980; 4: $475-86$.

24. Altura BM. Reticuloendothelial cells and host defense. Adv Microcirculation. 1980; 9: 252-294.
25. Altura BM. Reticuloendothelial system function and histamine release in shock and trauma: relationship to microcirculation. Klin Wochenshr 1982; 60: 882-90.

26. Altura BM, Gebrewold A, Carella A. A novel biologic immunomodulator HDFx, protects against lethal hemorrhage, endotoxins and traumatic shock: potential relevance to emerging diseases. Int J ClinExp Med. 2009 2: 266-79.

27. Altura BM, Carella A, Gebrewold A. HDFx: a novel biologic immunomodulator is therapeutically-effective in hemorrhage and intestinalischemic shock: importance of microcirculatory -immunological interactions and their potential implications for the warfighter and disaster victims. Int $J$ Clin Exp Med. 2011; 4: 331-40.

28. Altura BM, Carella A, Gebrewold A. HDFX; a novel biologic immunomodulator accelerates wound healing and is suggestive of unique regenerative powers: potential implications for the warfighter and disaster victims. Int J Clin Exp Med. 2012; 5: 289-95.

29. Altura BM, Gebrewola A, Carella A. HDFx: A recently discovered biologic and its potential use in prevention and treatment of hemorrhagic fever viruses and antibiotic-resistant superbugs. J Hematol Thromboembolic Dis. 2016; 4: 100252

30. Altura BM. HDFx: A novel immunomodulator and potential superbug super-warrior for hospitalized patients and battlefield casualties. Int $J$ Vaccines and Res. 2016; 3: 1-3.

31. Altura BM, Gebrewold A, Carella A, Altura BT. HDFx: A novel immunomodulator for the amelioration of hypovolemic shock and in the OR, cancer patients and on the battlefield. J Clin Med Ther1. 2016; e002.

32. Altura BM, Gebrewold A, Carella A, Altura BT. HDFx: A novel immunomodulator and potential fighter against cytokine storms in inflammatory and septic conditions in dogs and farm animals. Int J Vet Health Sci \& Res. 2017; 5: 1-3.

33. Metchnikoff E. Untersuchung ueber die intracellulare Verdauung beiwirbellosen Thieren. Arbeiten aus dem Zoologischen. Institut Wien. 1884; 5: 141-168.

34. Baue AE. Multiple Organ Failure. Patient Care and Prevention. Mosby Yearbook, Inc, St Louis. 1990.

35. Majno G, Joris I. Cells, Tissues and Diseases. Oxford University Press, New York. 2004

36. Murphy K, Weaver C. Janeway'slmmunology. ( $9^{\text {th }}$ edn.) Garland Press, New York. 2017 